\title{
A Theoretical Defence of Film Theory and Criticism
}

\author{
By Blair Miller
}

Spring 1999 Issue of KINEMA

\section{THE WORK OF INTERPRETATION: A THEORETICAL DEFENCE OF FILM THEORY AND CRITICISM}

READING on both critical theory and aesthetics has taught me is that anything -- namely art, and for my own personal purposes, movies -- can help us improve our moral wherewithal and self-understanding. Surely this is not what half of the artists intended their art to be used for, but nonetheless, critics and theorists do it all of the time, and with productive results. Yet, although those who believe in the didactic force of movies do so wholeheartedly, film theorists of the humanist sort are part of an overwhelming minority. This is especially true when weighed against the number of general moviegoers who see films as a means to get away from moral arguments, not to get into them. In other words, moviegoers often go above and beyond the duty of ignoring interpretive theories of movies; they are repulsed by such theories. What most people believe is that movies are fiction, and because of that, they teach us nothing.

In a brilliant essay about the dichotomy between the Hollywood marketplace and the university, Jonathan Rosenbaum observes that because the term "classic cinema" has

become a standard fixture in University prose, the necessity for [an interrogation which would finally construct its theory] has seemingly vanished, leaving the term to reap ideological havoc as it continues to validate an object that has not yet even achieved theoretical status. (1)

Film theory and criticism in itself has been taken for granted in a similar fashion. Those who see film theory and film interpretation as invalid misunderstand critical theory. That is partly due to the fact that film theory itself has not yet achieved theoretical status in the sense that it is readily understood and explicitly endorsed by those who apparently value it, let alone those who do not. Even T. S. Eliot notes that "a moderate number of persons have engaged in what is called 'critical' writing, but no conclusion is any more solidly established than it was [a century ago]." ${ }^{(2)}$ It has been the task of some philosophers who call themselves 'critical theorists' to try and articulate and validate the need for interpretive analysis as criticism, and it would serve film theorists and/or critics well to follow some of this work, since their profession relies wholly on interpretation.

Let us briefly outline the work of two significant contributors to the field of critical theory -- David Hoy, a prominent American philosopher, and Theodor Adorno, who, with Max Horkheimer, began the Frankfurt School in the 1930s and 1940s. Some of their groundbreaking work in the field of interpretative critical theory -- better known in philosophy as hermeneutics -- can serve as a useful foundation with which to help justify interpretation in film theory. Though an exercise in polemics, film theory and criticism should be a profession valued more widely than it is, because of its moral content and value. Through a series of similarities that link hermeneutics to interpretation of film, a moral strand within film theory and criticism will be visible, thus reemphasizing the moral force and responsibilities and that a film critic should adhere to. Self-proclaimed critics such as T. S. Eliot, David Browne, and Peter Wollen implicitly recognize a form of hermeneutical inquiry, and it is because of the very close links to an established form of philosophical inquiry that their pursuits can be further validated, and, in the words of Rosenbaum, achieve theoretical status.

As a critical theorist, David Hoy is very interested in elevating theory to theoretical status, so that such a process would both further justify and further articulate critical theory. What I am chiefly interested in with concern to Hoy's work is his defence of the work of Theodor Adorno, who serves to exemplify critical aesthetic theory in such a way that demonstrates the usefulness of art when it comes to understanding moral and critical issues. What I hope to do here, is to briefly outline Hoy's (and thus Adorno's) argument for hermeneutic interpretation. I only wish to outline the argument, so that characteristic features of it can be seen within the work of Eliot, Wollen, Browne and Rosenbaum -- theorists who are directly concerned, it will then seem, with the legitimacy of hermeneutics as it applies to artistic (and more specifically, film) theory. There are many different concepts that both Hoy and Adorno touch upon in order to justify theory of their 
sort, but what should be of primary concern here are two concepts. One, that hermeneutics serves to create anew the art form being analysed, and two, that it serves to unmask the myths surrounding the object of criticism in order to make the object more suitable to our individual and collective moral concerns. ${ }^{\left({ }^{3}\right.}$

It may go without saying that once one interprets something in a certain manner, that the interpretation will 'stick,' though often in the midst of ongoing debate. In other words, the object interpreted will forever recall those images or ideas that the interpretation is associated with. Indeed, it would be difficult for Adorno to henceforth read Homer's The Odyssey without seeing in it the plight of self-alienation and self-domination within which the modern self is trapped. ${ }^{(4)}$ With more specific attention to movies, Browne likely notices the moral politics of rigid social hierarchy and intolerance each time he views the scene of the meal at the Dry Fork Station in Stagecoach. ${ }^{(5)}$ Such observations may seem obvious -- perhaps even redundant -- but this type of relationship towards objects of interpretation means something important in a more abstract sense. Once one draws an interpretation from something, it can forever alter the conception of the thing interpreted. In other words, "the process of applying the [interpretation] inevitably transforms it. In general, hermeneutics is the analysis of this process and its conditions of possibility." ${ }^{(6)}$ The work interpreted is altered by the interpretation of it, and this empowers the interpreter -- the critic -- with a certain aesthetic creative power. This means that part of the message within the work of art would not exist without the critic's interpretation of it as such. The importance of this power will be seen below, in connection to criticism of art and/or film.

David Hoy touches upon this creative process during his analysis of Adorno in Critical Theory when he discusses determinate negation. Originally put forth by Hegel, determinate negation involves critique and interpretation of the object criticized, in order to produce something new from it. Because these interpretations are done by people, and are thus intertwined with our daily judgment and practices, determinate negation allows for a constant reshaping of those judgments and practices through interpretation. (In a very direct sense, this gives these interpretations a normative, moral force.) As Hoy describes the process that Adorno uses, a set of beliefs are not left behind for new ones, but rather it "breaks down ... for specific reasons internal to itself, and the effort to rectify itself leads to a particular reconfiguration that follows." ${ }^{(7)}$ This means that any interpretation made of an object criticized holds the keys to that interpretation within itself, but more importantly, that the object is 'reconfigured.' It is transformed by the creative powers of those interpreting. This is one of the characteristic elements of hermeneutics, and it is endorsed by Hoy in his discussion of Adorno.

Also, such a process would not be possible without a necessary interpretive outlook called the hermeneutics of suspicion. This outlook entails taking a 'suspicious' stance towards objects of criticism, so that such a stance will aim at uncovering hidden complexes of meaning that can only be found underneath the initial, intended meaning. Put this way, determinate negation is like extracting hidden meaning found somewhere inside the object of criticism. As Adorno puts it in The Dialectic of Enlightenment, interpretation must "[interpret] every image as writing. It shows how the admission of falsity is to be read in the lines of its features -- a confession that deprives it of its power and appropriates it for truth." ${ }^{(8)}$ This must entail finding hidden meaning behind the surface myths of immediacy, because if the object of criticism were collapsible on the surface, it would hold no initial force, and thus would not need any interpretation. In terms of film theory and criticism, the hermeneutics of suspicion is vital, since virtually every attempt at film theory aims at an interpretation that differs from immediate, responses that one gets from a film.

Although Adorno's (and Hoy's) use of determinate negation has very negative undertones, I do not wish to imply that this need always be the case. Indeed, Adorno uses determinate negation and hermeneutics to unmask the myth of enlightenment in order to expose it as something not positive at all. Terms like 'falsity' and 'breaks down' imply a constantly negative and deconstructivist tone. However, I only wish to point out that interpretation involves an act of creation on the part of the critic, and that this often involves unmasking the hidden meanings within the object of criticism. It does not need to be a negative critique. As Hoy's interlocutor, Thomas McCarthy points out, "it allows for a critical reconstruction ... through which [interpretations] are given sociocultural forms rather than simply dismantled." (9) Each time we watch a movie we do this, and we do it by creating new meaning for ourselves. It will shown below is that this process has a moral content. The fact that McCarthy sees determinate negation as a process during which interpretations are given social form gets closer at the idea that interpretive work carries with it a social and moral force. 
Before linking both Hoy and Adorno's work to film theory and criticism, I want to point out the connections between their work and the critical work of T. S. Eliot. Eliot's wording of the critical enterprise is very close to the views of Adorno and Hoy -- much closer than that of Wollen's and Browne's -- and can thus provide a useful bridge between hermeneutic critical theory as a philosophical enterprise, and hermeneutic critical theory as an artistic enterprise. As both a poet and an astute literary critic, Eliot himself represents both sides of the bifurcation that critical theory often undergoes by existing within either the artist, or the theorist/critic. Fitting then, that Eliot sees this division as illusory:

The poetic critic is criticizing poetry in order to create poetry ... It is fatuous to say that criticism is for the sake of 'creation' or creation for the sake of criticism. It is also fatuous to assume that there are ages of criticism and ages of creativeness, as if by plunging ourselves into intellectual darkness we were in better hopes of finding spiritual light. The two directions of sensibility are complementary; and as sensibility is rare, unpopular, and desirable, it is to be expected that the critic and the creative artist should frequently be the same person. ${ }^{(10)}$

Among other things, I see this to mean that the critic is endowed -- by the ambiguity of works of art -- with powers of creation comparable to that of the original artist. ${ }^{(11)}$ In Eliot's words, "A record ... is also an interpretation, a translation; for it must itself impose impressions upon us, and these impressions are as much created as transmitted by the criticism." (12) Interpretation is creative in nature, and since Adorno remains necessarily open-ended and fallible in his analyses, he would agree with Eliot in that "the question is not whether [the critic's] impressions are 'true' or 'false."'(13) True or false, that is, in the sense that they match up with the original intentions of the work of art. A concern about being 'true' to the original artist can dangerously restrict the power of the critic's interpretive skills to the extent that they become nonexistent.

The similarities between Eliot's conception of an artistic critic and that of Hoy's and Adorno's get at the very core of interpretation as determinate negation. In terms of film, the interpretation that one inevitably draws from a film transforms the way that film is understood. The moment you decide that Pleasantville is a metaphor for the political friction between left and right wing stereotypes, it is difficult to turn back. Signifiers appear everywhere -- even where they were invisible during a previous viewing -- and the film is no longer a naive tale of teenage freedom. With this fairly 'simple' interpretation of an equally 'simple' film, we now see how easy it can be to get involved in moral matters when interpreting a film.

But why is this so? Nick Browne, and his essay, "The Spectator-In-The-Text: The Rhetoric of Stagecoach," can get us a step closer. By focussing on a seemingly unimportant scene in Ford's film, Browne draws upon many implicit and subtle signs in order to illustrate certain moral conventions and restrictive social roles that play a role within society. By doing so, Browne believes that he has tapped "the guiding moral commentary of the film," (14) a place for the spectator to locate him or herself in relation to the narrator or narrative. For Browne, this 'place' "is defined through the variable force of identification" with certain characters within the film. ${ }^{(15)}$ Browne makes a very important move by calling this identification an emotional bond. By doing so he characterizes narrative suture as something which -- especially since one need not identify with a character of similar view to one's own -- can evoke issues of morality within the spectator/interpreter. These issues, as Browne has it, construct certain moral judgments and expectations about how the narrative should unfold itself. Because these judgments concern the well being of characters within the film, a decision to uphold, or even disregard, certain moral judgments and expectations about the narrative constitutes a moral decision. A decision to side with either Lucy or Dallas can be a decision of no other type; the decision holds distinct, normative consequences for one's positioning within what Browne calls "the moral order of the text."(16) This is not unlike the unquestionably moral move we make to position ourselves in respect to political issues that do not affect us personally. ${ }^{(17)}$

More needs to be said though, about the connection between film theory and/or criticism and the hermeneutic work endorsed by Hoy and Adorno. Peter Wollen and his discussion about the auteur theory ${ }^{(18)}$ can be of much use here. First, Wollen can be connected to hermeneutics because he believes that an audience's interpretation can indeed transform the film being viewed:

The auteur theory, as I conceive it, insists that the spectator has to work at reading the text ... In these cases, in a certain sense, the film changes, it becomes another film -- as far as experience of it is concerned. It is no longer possible to look at it 'with the same eyes'. 
In this sense, Wollen is a hermeneutic film theorist. In fact, his interesting take on the auteur theory posits the audience (read: critic) as auteur, as the creative hero. It is the audience that makes the distinctions between different directors plausible and legitimate.

But Wollen argues for hermeneutics and determinate negation in a different sense as well, because he sees the audience as involved in a process "of decipherment, decryptment"(19) that requires extraction of hidden meaning. Just as noted above with Adorno, the critic must seek out "an unconscious, unintended meaning [that is] decoded in the film, usually to the surprise of the individual involved." ${ }^{(20)}$ This is especially important to both hermeneutics and film theory, because this means that the directors, and their visions themselves are not identical to legitimate interpretations of their films, and Wollen notes this in the passage that succeeds the one mentioned above. Adorno's view of The Odyssey is not to be confused with Homer's, nor is Tania Modleski's view of Hitchcock to be confused with Hitchcock's conscious intentions while making any of his films.

And, just as with Browne, these interpretations carry moral value, in the sense that they help us cope with the world around us and improve our self-understanding:

The world itself is an untidy place, full of loose ends, but the artefact can tie all these loose ends together and thus convey to us a meaningful truth, an insight, which enables us to go back to the real world with a reordered and recycled experience which will enable us to cope better, live more fully, and so on. In this way art is given a humanistic function, which guarantees its value. ${ }^{(21)}$

Jonathan Rosenbaum, one of our more 'moral' film critics, argues a similar idea concerning the moral force of film: "... I believe movies are potentially important enough to be tested in relation to life, not simply accepted as loose approximations or escapist alternatives." ${ }^{(22)}$ It is in Rosenbaum that I find my main point: watching (read: interpreting) movies constitutes making a moral judgment about both the film's subject matter and the world around us. Rosenbaum sees the uncanny way in which "our news resembles our so-called entertainment and vice versa" ${ }^{(23)}$ as an indication of the political power that movies hold. Indeed, one cringes upon noticing the eerie smoothness with which a pretend CNN and a film narrative like Independence Day's push each other along. ${ }^{(24)}$ And, what is perhaps the best indication of things moral are the consequences that follow when such moral content is unnoticed, or even shunned. As Rosenbaum divulges:

"Keep your politics out of your reviews," wrote an irritated reader in 1993 (as if he or I had a choice in the matter). "It'll destroy your credibility." But keeping politics out of movie reviews, I'd argue, is precisely what makes it easy to cheer and celebrate such CNN "movies" or "turkey shoots" -- as OPERATION DESERT STORM and WAR IN THE GULF. ${ }^{25)}$

What happens when our attitudes or abilities within a moral sphere dwindle? The lines between what was once acceptable and what was once morally objectionable begin to dwindle as well. I do not mean to imply that the film critic/theorist alone can re-trace these lines, but the fact that Rosenbaum can call attention to such issues from within interpretations of films says a great deal about the moral force of interpretation.

Without interpretive work, Rosenbaum would not be able to draw these inferences from movies. Because of this, interpretation, or hermeneutics carries with it a moral force, and the critic is at its core. As I stated above, in my discussion of Adorno and Hoy, the person interpreting possesses creative power, in the sense that they can create new meaning for an object of criticism -- a meaning that is hidden. Linked to a need to use film in order to articulate things that have gone morally astray (as Rosenbaum has noted above), this power means that interpretation of movies should be, and thus is, moral. As the old adage goes, with great power comes great responsibility. With responsibility comes a moral force; a film theorist could examine countless other interpretations of a film other than his or her own, but they make a decision to endorse the one that they do. This is something more than taste. It is a moral judgment, because, as Rosenbaum states, we can "use films as a way to speak about other things in our society: racism, xenophobia, targeting, tribalism..."(26) The interpretations which we use to do so is no trivial matter: "To go to the cinema, to read a book, or to listen to music is to be a partisan. Evaluation cannot be impartial." (27) Many more philosophers other than Hoy and Adorno use interpretations of things not immediately useful in order to help us understand ourselves and the world we live in. As noted above, with McCarthy, determinate negation allows a critic to 
give interpretations "sociocultural forms." Critical theorists appropriate certain things for moral use. So do film theorists and film critics, and to deny such moral relevance within film is to make an equally significant moral decision.

\section{Notes}

1. Jonathan Rosenbaum, Movies as Politics (Los Angeles; University of California at Berkeley Press, 1997), 242.

2. T. S. Eliot, The Sacred Wood -- Essays on Poetry and Criticism, 2nd ed. (London; Faber and Faber Limited, 1960), xiii.

3. I should note here that there mere use of the word 'theory' in conjunction with Hoy and/or Adorno may imply something which both men are adverse to. In philosophical terms, both theorists are against the positing of universal, absolute theoretical structures with which one can draw inferences about the object of inquiry. I recognize this, and side with Hoy and Adorno in this respect. However, I still believe that their work constitutes a theory, albeit a much more fallible one, without the objective -- and often reclusive -- standards that even some film theorists find comfort in. The mere assertion that works of art like The Odyssey serve as some sort of hermeneutic indication of a form of human reason says a great deal about the 'looser' theory that I am arguing for in this paper -- the idea that interpretations of films can serve as useful within moral discourses. What I have just said in general terms Hoy says as well, with specific reference to Adorno's "aspiration to work out a 'theory of theory." See David Hoy and Thomas McCarthy, Critical Theory (Cambridge, Mass.; Blackwell Publishers Inc., 1994), 124.

4. See Max Horkheimer and Theodor Adorno, Odysseus or Myth and Enlightenment" from The Dialectic of Enlightenment, Cumming, trans. (New York; Herder \&Herder, 1972), 43-80.

5. See Nick Browne, "The Spectator-in-the-text: The Rhetoric of Stagecoach" from Film Theory and Criticism -- Introductory Readings, Leo Braudy and Marshall Coen, eds. (Oxford; Oxford University Press, 1999), 148-163.

6. The Cambridge Dictionary of Philosophy, Robert Audi, ed. (Cambridge; Cambridge University Press, 1995), 323

7. David Hoy and Thomas McCarthy, Critical Theory, 122.

8. Max Horkheimer and Theodor Adorno, The Dialectic of Enlightenment, 24.

9. Hoy and McCarthy, 8.

10. T. S. Eliot, The Sacred Wood -- Essays on Poetry and Criticism, 13.

11. This should, by no means, diminish the value of the work of the artist, but rather amplify the value of the work of the critic. As loathed as they often are by the film industry (especially artists like directors and actors), it is pretentious at best to assume that a critical reshaping of one's performance does not alter the public or private perception of the work of art.

12. Eliot, 2-3.

13. Ibid, 4 .

14. Browne, "The Spectator-in-the-text: The Rhetoric of Stagecoach", 159.

15. Ibid., 160. 16. Ibid., 162.

17. For example, a North American's ethical judgment concerning issues internal to the former Yugoslavia constitutes a moral judgment on moral matters. I do not wish to begin a discussion about universal moral standards versus moral ethnocentrism. Some may view North American input on foreign matters as morally incongruent. However, this in itself implies that a similar moral incongruence between 'real life' matters and those of fictional characters still constitutes a decision about a moral issue, and thus gives such decision a 
moral force. (Two sets of moral beliefs being incongruent does not mean that a moral judgment from one set directed towards the other is amoral.)

18. In his Signs and Meaning in the Cinema

19. Peter Wollen, "The Auteur Theory" from Film Theory and Criticism, 530.

20. Ibid., 532. 21. Ibid., 534. 22. Rosenbaum, 7. 23. Ibid., 3.

24. It should be noted that this is a growing trend, at least in Hollywood. Both Deep Impact and Armageddon utilize very realistic impersonations of CNBC and other news networks in order to fuel their narrative, and with amazing ease. In fact, it is my opinion that within a film, people are more drawn to the news than they are to the real-life narratives that the actual CNN reports. The sheepish comments people make about both Wag the Dog and Primary Colours as somehow anticipating Clinton's promiscuity seem to hint towards a strange ability to believe in fiction more than in 'real life.'

25. Rosenbaum, Movies as Politics, 3. 26. Ibid., 7. 27. Wollen, 544.

\section{Author Information}

Blair MILLER is a Honours philosophy and film student at Wilfrid Laurier University in Waterloo, Ontario, Canada. His main interests of study are aesthetics, art theory and film direction. He also writes scripts. He plans to either attend a film school or pursue graduate work in philosophy or film studies. 